\title{
Intrinsic Risk Factors for Bovine Tropical Theileriosis in Indian Cattle: A Meta-Analysis
}

\author{
Gajendra N. Bhangale*, K.C. Bhanu Prakash and Ankush R. Dhabale \\ Department of Parasitology, College of Veterinary and Animal Sciences, Parbhani, MAFSU, Nagpur, INDIA \\ *Corresponding author: GN Bhangale; E-mail: gajumanu@gmail.com
}

Received: 26 March, 2021

Revised: 19 April, 2021

Accepted: 25 April, 2021

\begin{abstract}
Meta-analysis of systematically selected studies published during 2015-2020 on the prevalence of bovine tropical theileriosis from Indian cattle was done. It was found that age, sex and breed of cattle are important risk factors to get infected with Thieleria sp. Adult cattle are found at higher risk of getting infected with BTT than the younger stocks with an odds ratio of 2.062, however as regards sex of the cattle is concerned cows are little more susceptible to BTT than bullocks / bulls with an odds ratio of 1.632. The breed factor of cattle has shown that exotic/ crossbred cattle are more prone to contract BTT with an odds ratio of 2.113. The meta-analysis showed no publication bias.
\end{abstract}

\section{HIGHLIGHTS}

0 Age, sex, and breed of cattle are major risk factors for Theileriosis in Indian cattle.

O Very few studies recorded those risk factors.

(0 More studies on epidemiological aspect of bovine tropical Theileriosis are needed.

Keywords: Theileria, cattle, risk factors, MetaXL

In dairy animals vector borne haemoprotozoan diseases are of prime importance considering their impact on production and substantial economic costs ultimately upsetting the dairy enterprises. With significant morbidity and mortality in its ruminant hosts, theileriosis is a major impediment in dairy industry globally (Demessie and Derso, 2015). Bovine tropical Theileriosis (BTT) is a tick borne haemprotozoan disease caused by an apicomplexan parasite Theileria spp., the obligate intracellular protozoan parasite which infects domestic and wild ruminanats. The ticks of Ixodidiae family are the vectors of this protozoa and they have a complex life cycle both in vertebrate and invertebrate hosts. Amongst several species of Theileria genus that infect cattle, T. parva and T. annulata are most pathogenic and prevalent species. BTT is very lethal and debilitating hemoprotozoon disease infecting cattle which is caused by $T$. annulata and transmitted by Hyalomma sp ticks (Mans et al., 2015). The disease is clinically characterized by high fever and enlargement of superficial lymph nodes. As per earlier estimate about 33 million Indian cattle are at risk of BTT (Minjauw and McLeod, 2003) and annual economic losses due to this disease approximately amounts to ₹ 8426 crores in India (Narladkar, 2015).

As the sub-tropical climatic conditions of Indian subcontinent are extremely conducive for ticks and therefore for tick borne disease, BTT is a major disease dairy animals are exposed to in this region including India. Several earlier studies from across India reported prevalence of BTT of different extent attributed to various risk factors viz. age, sex, breed, season, management practices etc. (Gul et al., 2015). Various factors such as managament practices, sex, health status, nutritional

How to cite this article: Bhangale, G.N., Prakash, B.K.C. and Dhabale A.R. (2021). Intrinsic risk factors for bovine tropical theileriosis in Indian cattle: A meta-analysis. J. Anim. Res., 11(3): 497-503.

Source of Support: None; Conflict of Interest: None

(क) 9 
deficits, breed, herd size, agro-climate (humidity, temperature) directly affects the livestock health and pose them to get this disease (Ghosh and Nagar 2014, Ayadi et al., 2016). Considering its importance epidemiological studies have since long being conducted in India to estimate its spread so as to formulate effective control strategies to minimize the losses incurred by BTT.

The present study has detailed on animal bio-markers as the risk factors for BTT in India though meta-analysis approach based on earlier published reports.

\section{MATERIALS AND METHODS}

Present study is based on meta-analysis of earlier reports on risk factors for BTT in India. This meta-analysis was conducted according to criteria laid down under PRISMA Guidelines (Moher et al., 2009). The studies were selected for this meta-analysis were spanned over years 2015 2020. The studies were selected through a systematic search from online free databases viz. GoogleScholar, PubMed, IndianJournals. The keys used for this search were Theileria, Theileriosis, Bovine, Cattle, India with combinations by using Boolean words i.e. AND, OR. the criteria for selection of studies were such that the study to be selected should have reported prevalence of Theileriosis in cattle based various risk factors including age, sex and breed as the biomarkers of the cattle. The search and strategic selection based on the aforementioned criteria yielded 12 studies for final meta-analysis.

The requisite data on the BTT prevalence estimates based

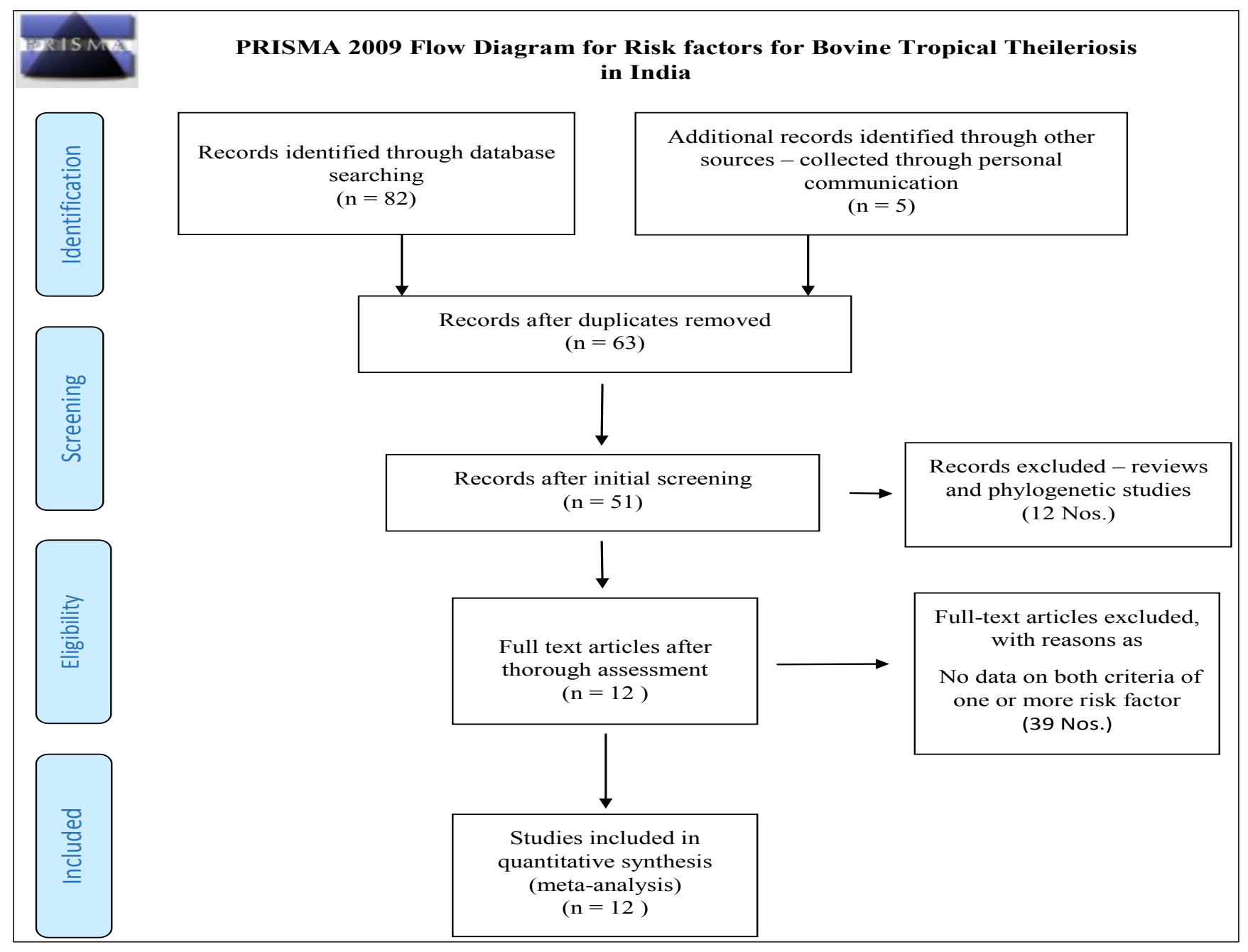

Moher et al. (2009). www.prisma-statement.org 
on risk factors were extracted from the selected studies and entered in an MS-excel sheet. Depending on the extent of heterogeneity, the random effects model and fixed effects model was employed for this meta-analysis. When heterogeneity was above $75 \%$, random effects model was employed otherwise fixed effect model was used.

Risk factors for BTT as age, sex, breed was considered for this analysis and accordingly data was categorized. Studies with exact and essentially with both the number of animals tested and the number animals found positive for at least one of these factors was included in this analysis. Individual spreadsheet for data on each of the risk factors was prepared and subjected to meta-analysis. Meta-analysis was performed on MetaXL add-in with the help the command NumOR and results were presented through forest plot. Heterogeneity and publication bias were assessed and presented accordingly.

Table 1: Characteristics of the included studies on risk factor wise prevalence of BTT in India

\begin{tabular}{|c|c|c|c|c|}
\hline \multirow{2}{*}{$\begin{array}{l}\text { Risk Factor - Age } \\
\text { Study name }\end{array}$} & \multicolumn{2}{|c|}{ Adult } & \multicolumn{2}{|c|}{ Young } \\
\hline & Total & Positive & Total & Positive \\
\hline Kundave et al., 2015 & 74 & 59 & 15 & 7 \\
\hline Tuli et al., 2015 & 840 & 243 & 241 & 33 \\
\hline Agrawal et al., 2016 & 83 & 26 & 55 & 2 \\
\hline Naik et al., 2016 & 115 & 28 & 35 & 7 \\
\hline Dadhich et al., 2017 & 210 & 41 & 90 & 27 \\
\hline Brahma et al., 2018 & 314 & 189 & 249 & 86 \\
\hline Debbarma et al., 2020 & 163 & 49 & 147 & 22 \\
\hline Farooq et al., 2019 & 921 & 57 & 762 & 16 \\
\hline Khawale et al., 2019 & 60 & 13 & 7 & 2 \\
\hline Selim et al., 2020 & 140 & 81 & 86 & 43 \\
\hline Risk Factor - Sex & \multicolumn{2}{|c|}{ Female } & \multicolumn{2}{|c|}{ Male } \\
\hline Study name & Total & Positive & Total & Positive \\
\hline Tuli et al., 2015 & 1053 & 322 & 225 & 52 \\
\hline Agrawal et al., 2016 & 104 & 26 & 34 & 2 \\
\hline Naik et al., 2016 & 110 & 28 & 40 & 7 \\
\hline Maharana et al., 2016 & 42 & 14 & 76 & 4 \\
\hline Debbarma et al., 2020 & 254 & 63 & 56 & 8 \\
\hline Brahmbhatt et al., 2019 & 48 & 10 & 16 & 3 \\
\hline Farooq et al., 2019 & 1492 & 67 & 191 & 6 \\
\hline Khawale et al., 2019 & 62 & 13 & 5 & 2 \\
\hline Selim et al., 2020 & 215 & 118 & 11 & 6 \\
\hline Risk Factor - Breed & \multicolumn{2}{|c|}{$\begin{array}{c}\text { Crossbred / } \\
\text { Exotic Breed } \\
\end{array}$} & \multicolumn{2}{|c|}{ Indigenous Breed } \\
\hline Study name & Total & Positive & Total & Positive \\
\hline Tuli et al., 2015 & 972 & 315 & 56 & 11 \\
\hline
\end{tabular}

\begin{tabular}{lllll} 
Agrawal et al., 2016 & 125 & 27 & 13 & 1 \\
Naik et al., 2016 & 97 & 27 & 53 & 8 \\
Farooq et al., 2019 & 1635 & 72 & 48 & 1 \\
Khawale et al., 2019 & 65 & 15 & 2 & 0 \\
Selim et al., 2020 & 220 & 122 & 6 & 2 \\
\hline
\end{tabular}

\section{RESULTS AND DISCUSSION}

Through the systematic search and following selection criteria amongst 87 studies reviewed from databases 12 were eligible for this meta-analysis (Fig 1). The characteristics of the selected studies and details of each are given in Table 1. Meta-analysis results are also presented in Table 2 wherein the log odds ratio for each of risk factor along with heterogeneity data and publication bias accounts are given. Publication bias was presented through LFK Index and Doi plot and depicted through Figures 5, 6, 7 .

Table 2: Results of meta-analysis of risk factors of BTT in India

\begin{tabular}{|c|c|c|c|c|c|c|c|}
\hline 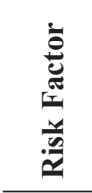 & 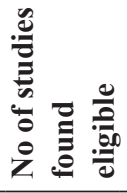 & 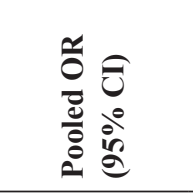 & o & $\underbrace{e^{e}}_{\mathfrak{v}}$ & 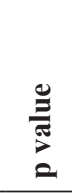 & 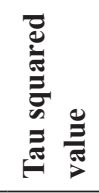 & 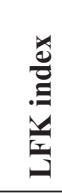 \\
\hline Age & 10 & $\begin{array}{l}2.062(1.352 \\
-3.145)\end{array}$ & 38.729 & 76.76 & 0.00 & 0.31 & 0.36 \\
\hline Sex & 09 & $\begin{array}{l}1.632(1.266 \\
-2.104)\end{array}$ & 13.923 & 42.54 & 0.08 & 0.15 & 0.27 \\
\hline Breed & 06 & $\begin{array}{l}2.113(1.315- \\
3.396)\end{array}$ & 0.304 & 0.00 & 0.99 & 0.00 & 0.75 \\
\hline
\end{tabular}

\section{Age as a risk factor}

Results of this meta-analysis revealed that age plays an important role in development of Theileriosis in cattle. Adult cattle are found twice at risk for BTT than the younger stocks with an odds ratio of 2.062 (95\% CI $1.352-3.145)$ which was highly significant $(\mathrm{Q}=38.729$; $\mathrm{p}=0.0)$ with substantial heterogeneity $\left(\mathrm{I}^{2}=476.76 \%\right)$. As regards age factor in the distribution of BTT these findings correspond to earlier reports by Panda et al. (2011); Kumar (2012); Agrawal (2016); Kolte et al. (2017); Ghosh et al. (2020). However, several other studies contradicted these findings (Salih et al., 2013; Velusamy et al., 2014). Since adult cattle particularly cows are usually subjected to 
milk production, the stress due to lactation and pregnancy will be a major predisposing factor for getting BTT and other infectious disease. Additionally, higher exposure of vectors to adult cattle due to open grazing is also an important contributing factor. On the other hand, young stock which are generally raised on intensive feeding and confined housing are less prone to attack by vectors and therby vector borne diseases (Bhutto et al., 2010). Even earlier reports justifying the age related resistance in young stock to most of the tick borne protozoan and rickettsial diseases including T.annulata (Dumanli et al., 2005).

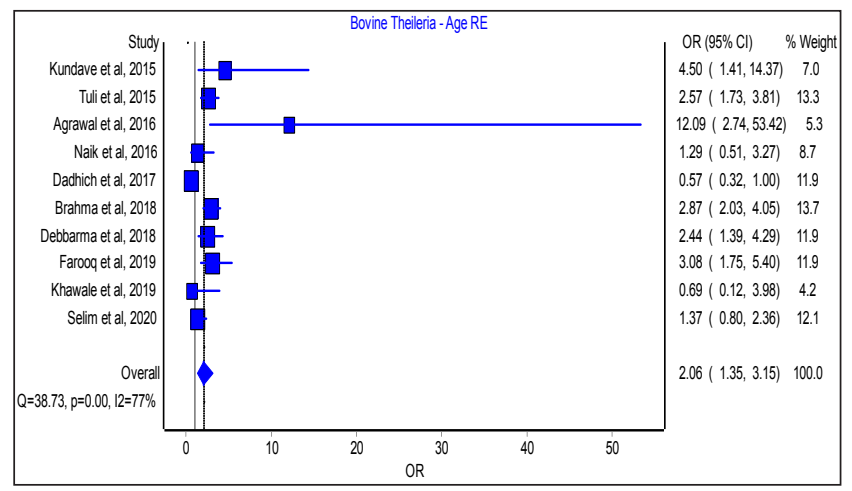

Fig. 2: Forest plot depicting age as a risk factor of BTT in Indian cattle

\section{Sex as a risk factor}

Sex of cattle was found to have moderate impact to make the animal susceptible for BTT. It was estimated that cows are little more susceptible to BTT than bullocks / bulls with an odds ratio of 1.632 (95\% CI $1.266-2.104)$. However, with lower heterogeneity between studies $\left(\mathrm{I}^{2}=42.54 \%\right)$ this estimate was non-significant $(\mathrm{Q}=13.923$; $\mathrm{p}=0.08)$. These findings also corroborates with earlier reports by Zaman et al. (2020). However, the rationale for such distribution may be attributed to certain intrinsic factors such as hormones may have a role to play (Kumar et al., 2017). As males are either culled or utilized for drought purposes as against cows which are raised longer for milk production and breeding are under persistent physiological stress due to pregnancy and/or lactation. This stress along with suppression of immunity may predispose those cows to higher risk of getting infected with BTT (Kamani et al., 2010, Ghosh et al., 2018).

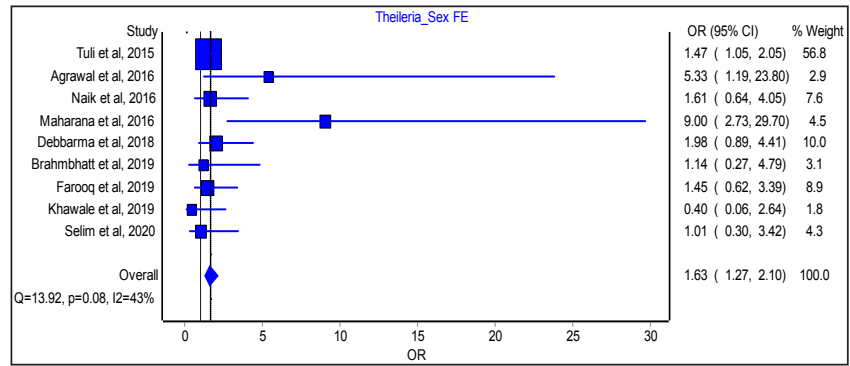

Fig. 3: Forest plot depicting sex as a risk factor of BTT in Indian cattle

\section{Breed as a risk factor}

As being reported since long, exotic / crossbred cattle are more prone to contract BTT with an odds ratio of 2.113 $(95 \%$ CI $=1.315-3.396)$ which was even supported by several earlier evidences based on molecular studies (Kumar et al., 2017). Similarly, the estimates of current meta-analysis also seconded this, however there is absence of heterogeneity $\left(\mathrm{I}^{2}=0 \%\right)$ between the studies under this meta-analysis. The results on the basis of $\mathrm{Q}$ statistics $(0.304 ; p=0.99)$ are non-significant. Yet the current metaanalysis revealed that exotic and cross bred cattle are two fold at risk of getting infected with BTT than those cattle of domestic breeds. Similar trends were reported earlier by Salih et al., (2013); Ghosh et al., (2018); Gharbi et al., (2020). The observations of current study have strongly justified the earlier report by Kolte et al., (2017) wherein they have validated that germplasm of the cattle was crucial for the infection of Theileriosis and found that carrier crossbred cattle attracts more maintenance costs to the dairy enterprises. Furthermore, earlier reports also pointed out low case fatality and infection rates in local breeds while the higher morbidity and mortality in exotic and crossbred cattle (Jensen et al., 2007).

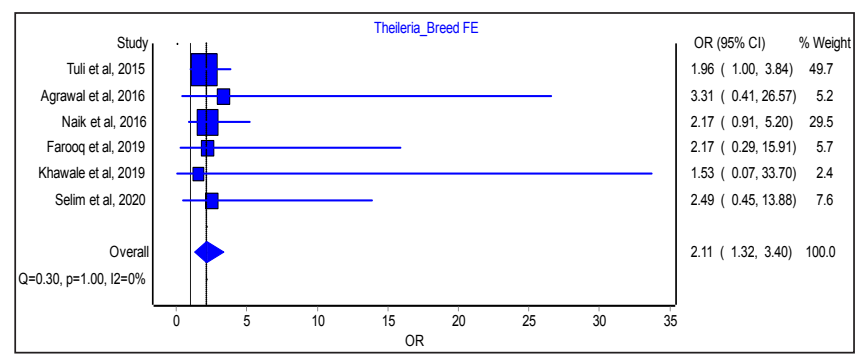

Fig. 4: Forest plot depicting breed as a risk factor of BTT in Indian cattle 
Since the $95 \%$ confidence intervals of odds ratios for all the factors under this study are more than 1 and did not include 1 (i.e. $\mathrm{OR} \neq 1$ ), the effects size i.e. pooled ORs are significant at $5 \%$ level of significance.

\section{Publication bias}

The meta-analysis conducted for individual risk factor with selected set of studies for each of them has also tested for publication bias and presented through LFK Index and Doi plot individually. The LFK indices for each of them are in the range of $0-1$ which signifies no publication bias (Table 2). Also visual observation of Doi plots also seconded the absence of publication bias between the studies included for this analysis (Figs. 2, 3, 4). No publication bias in meta-analysis of risk factors of BTT in Indian cattle was found for individual analysis conducted (Barendregt and Doi, 2011 and Kanamori et al., 2018).

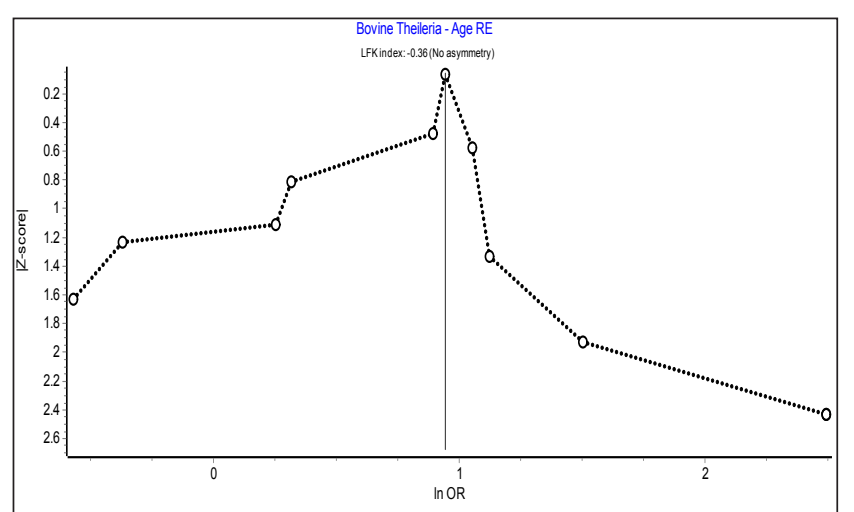

Fig. 5: Doi plot and LFK index for publication bias in meta analysis of age as risk factor for BTT

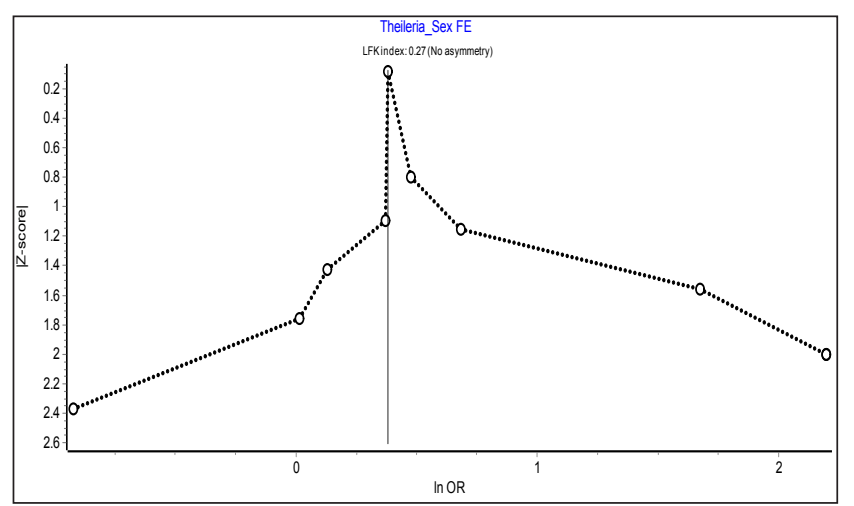

Fig. 6: Doi plot and LFK index for publication bias in metaanalysis of sex as risk factor for BTT

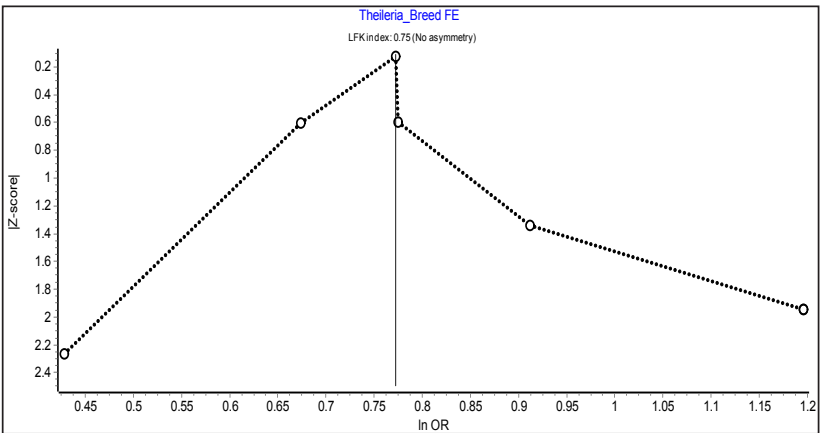

Fig. 7: Doi plot and LFK index for publication bias in metaanalysis of breed as risk factor for BTT

\section{CONCLUSION}

It is herewith concluded that among the variables viz. age, sex, breed of cattle considered to be potential risk factors for BTT in Indian cattle, age and sex are found significant association with the occurrence of Theileriosis. On the other hand, even if breed of cattle has shown non-significant relation with the BTT incidence, its importance as a risk factor based on evidence from previous studies cannot be overruled. Though meta-analysis gives pooled estimates, the evidence obtained through it depends primarily on the qualities of primary studies included in it. To overcome this, further studies with appropriate sampling from each of the risk groups need to be undertaken to build a concrete evidence for better understanding of epidemiology of BTT.

\section{ACKNOWLEDGMENTS}

Authors express gratitude to the authorities of COVAS, Parbhani and MAFSU, Nagpur for providing necessary facilities for this study.

\section{REFERENCES}

Agrawal. V., Das, G., Shrivastav, A.B., Singh, N. and Singh, A.P. 2016. Investigations on prevalence of theileriosis in cattle by polymerase chain reaction. J. Vet. Parasitol., 30(1): 1-5.

Agrawal, Vivek. 2016. Haemoprotozoan infections with special reference to trypanosomosis and its molecular diagnosis in dairy animals. PhD Thesis submitted to Nanaji Deshmukh Veterinary Science University, Jabalpur https://krishikosh. egranth.ac.in/handle/1/5810005435

Ayadi, O., Rjeibi, M.A., Elfegoun, M.C.B. and Gharbi, M. 2017. Prevalence and risk factors of tropical theileriosis, and 
sequencing of Theileria annulata, the causative pathogen, in Setif region (Algeria) before and after tick season. Santé Animale Et Épidémiologie, 69(4): 161-166

Barendregt, J.J. and Doi, S.A.R. 2011. MetaXL User Guide Version 5.3. EpiGear International Pty Ltd., Sunrise Beach, Queensland, Australia, 2011-2016.

Bhutto, B., Gadahi, J.A., Shah, G., Dewani, P. and Arijo, A.G. 2010. Field investigation on the prevalence of trypanosomiasis in camels in relation to sex, age, breed and herd size. Pakistan Vet. J., 30(3): 175-177.

Brahma, J., Baishya, B.C., Phukan, A., Mahato, G., Deka, D.K. and Goswami, S. 2018. Prevalence of Theileria orientalis in crossbred cattle of Kamrup district of Assam. Int. J. Chem. Stud., 6(3): 1791-1794.

Brahmbhatt, N.N., Kumar, B., Thakre, B.K., Parmar, V., Choravada, D.R. and Patel, J.A. 2019. Clinico-hematological study of Theileriosis in Gir and Jaffrabadi calves. Ind. J. Vet. Sci. Biotechnol., 14(4): 36-39.

Dadhich, S.R., Mehta, H.K., Gupta, A.K. and Jain, R.K. 2017. Prevalence of Theileria annulata infection in cross bred cows of indore district of Madhya Pradesh. J. Anim. Res., 7(6): 1145-1148.

Debbarma, A., Pandit, S., Jas, R., Baidya, S., Mandal, S.C., Jana, P.C. and Das, M. 2020. Prevalence of tick-borne haemoparasitic diseases in cattle of West Bengal, India. Biol. Rhythm Res., 51(2): 310-317.

Demessie, Y. and Derso, S. 2015. Tick borne hemoparasitic diseases of ruminants: A Review. Adv. Bio. Res., 9(4): 210224.

Dumanli, N., Aktas, M., Cetinkaya, B., Cakmak, A., Koroglu, E., Saki, C.E., Erdogmus, Z., Nalbantoglu, S., Ongor, H., Simşek, S. and Karahan, M. 2005. Prevalence and distribution of tropical theileriosis in eastern Turkey. Vet. Parasitol., 127(1): 9-15.

Farooq, U., Tufani, N.A., Malik, H.U. and Mir, M.S. 2019. Clinical and Morpho-Molecular epidemiology of bovine theileriosis in Kashmir, India. Ind. J. Ani. Res., 53 (3): 375381

Gharbi, M., Darghouth, M.A., Elati, K., AL-Hosary, A.A.T., Ayadi, O., Salih, D.A., El Hussein, A.M., Mhadhbi, M., Khbou, M.K., Hassan, S.M., Obara, I., Ahmed, L.S. and Ahmed, J. 2020. Current status of tropical theileriosis in Northern Africa: A review of recent epidemiological investigations and implications for control. Transb. Emerg. Dis., 67(Suppl. 1): 8- 25.

Ghosh, S., Patra, G., Borthakur, S.K., Behera, P., Tolenkhomba, T.C., Deka, A., Khare, R.K. and Biswas, P. 2020. Prevalence of haemoprotozoa in cattle of Mizoram, India. Biol. Rhythm Res., 1: 76-87.
Ghosh, S. and Nagar, G. 2014. Problem of ticks and tick-borne diseases in India with special emphasis on progress in tick control research: A review. J. Vector Borne Dis., 51: 259-270.

Gul, N., Ayaz, S., Gul, I., Adnan, M., Shams, S. and Akbar, N. 2015. Tropical theileriosis and east coast fever in cattle: present, past and future perspective. Int. J. Curr. Micro. Applied Sci., 4(8): 1000-1018.

Jensen, K., Paxton, E., Waddington, D., Talbot, R., Darghouth, M.A. and Glass, E.J. 2007. Difference in the transcriptional responses induced by Theileria annulata infected in bovine monocytes derived from resistant and susceptibe cattle breeds. Int. J. Parasitol., 39: 425-432

Kamani, J., Sannusi, A., Egwu, O.K., Dogo, G.I., Tanko, T.J., Kemza, S., Tafarki, A.E. and Gbise, D.S. 2010. Prevalence and significance of haemoparasitic infections of cattle in North-Central, Nigeria. Vet. World, 3(10): 445-448.

Kanamori, L.F., Barendregt, J.J. and Doi, S.A.R. 2018. A new improved graphical and quantitative method for detecting bias in meta-analysis. Int. J. Evid. Based Health, 16(4): 195203.

Khawale, T.S., Siddiqui, M.F.M.F., Borikar, S.T., Sakhare, M.P., Rajurkar, S.R., Chigure, G.M. and Shafi, T.A. 2019 Study of occurrence of theileriosis in cattle from Parbhani district, Maharashtra, India. The Pharma. Innov. J., 8(9): 171-173

Kolte, S.W., Larcombe, S.D., Jadhao, S.G., Magar, S.P., Warthi, G., Kurkure, N.V., Glass, E.J. and Shiels, B.R. 2017. PCR diagnosis of tick-borne pathogens in Maharashtra state, India indicates fitness cost associated with carrier infections is greater for crossbreed than native cattle breeds. PLOS ONE, 12(3): e 0174595.

Kumar, A., Gaur, G.K., Gandham, R.K., Panigrahi, M., Ghosh, S., Saravanan, B.C., Bhushan, B., Tiwari, A.K., Sulabh, S., Priya, B., Asaf, V.N.M., Gupta, J.P., Wani, S.A., Sahu, A.R. and Sahoo, A.P. 2017. Global gene expression profile of peripheral blood mononuclear cells challenged with Theileria annulata in crossbred and indigenous cattle. Infection Genetics and Evolution, 47: 9-18.

Kumar, Sanjay. 2012 A Study on some aspects of theileriosis in bovines with special reference to epidemiology, haemato biochemical changes and therapeutics. MVSc thesis submitted to U.P. Pt. Deen Dayal Upadhyaya Pashu Chikitsa Vigyan Vishwavidyalay Evam Go-Anusandhan Sansthan, Mathura. http://krishikosh.egranth.ac.in/handle/1/5810031212

Kundave, V.R., Patel, A.K., Patel, P.V., Hasnani, J.J. and Joshi, C.G. 2015. Detection of theileriosis in cattle and buffaloes by polymerase chain reaction. J. Parasit. Dis., 39(3): 508-513.

Maharana, B.R., Kumar, B., Prasad, A., Patbandha, T.K., Sudhakar, N.R., Joseph, J.P. and Patel, B.R. 2016. Prevalence and assessment of risk factors for haemoprotozoan infections 
in cattle and buffaloes of South-West Gujarat, India. Ind. $J$. Anim. Res., 50(5): 733-739.

Mans, B.J., Pienaar, R. and Latif, A.A. 2015. A review of Theileria diagnostics and epidemiology. Int. J. Parasitol. Parasites. Wildl., 4(1): 104-118.

Minjauw, B. and McLeod, A. 2003. Tick-borne diseases and poverty: The impact of ticks and tick-borne diseases on the livelihood of small scale and marginal livestock owners in India and eastern and southern Africa. Research Report, DFID-AHP. UK: Centre for Tropical Veterinary Medicine, University of Edinburgh 2003; pp. 116.

Moher, D., Liberati, A., Tetzlaff, J. and Altman, D.G. 2009. Preferred reporting items for systematic reviews and metaanalyses: the PRISMA statement. J. Clin. Epidemiol., 339: b2535.

Naik, B.S., Maiti, S.K. and Raghuvanshi, P.D.S. 2016. Prevalence of Tropical Theileriosis in Cattle in Chhattisgarh State. J. Anim. Res., 6(6): 1043-1045.

Narladkar, B.W. 2018. Projected economic losses due to vector and vector-borne parasitic diseases in livestock of India and its significance in implementing the concept of integrated practices for vector management, Vet. World, 11(2): 151-160.

Panda, S.K., Sahu, B., Ranjan, R., Acharya, A.P. and Rath, S.K. 2011. Prevalence and clinicopathological study of theileriosis in bovine in coastal areas of Orissa. Ind. J. Vet. Pathol., 35(2): 128-132, 2011.
Salih, D.A., Ali, A.M., Hassan, S.M., Mukhtar, M.M., Hussein, A.M.E., Seitzer, U. and Ahmed, J. 2013. Tropical theileriosis (Theileria annulata infection of cattle) in Khartoum state, Sudan: Risk factors. Sudan J. Vet. Res., 28: 51-52.

Selim, A.M., Das, M., Senapati, S.K., Jena, G.R., Mishra, C., Mohanty, B., Panda, S.K. and Patra, R.C. 2020. Molecular epidemiology, risk factors and hematological evaluation of asymptomatic Theileria annulata infected cattlein Odisha, India. Iranian J. Vet. Res., 21(4-73): 250-256

Tuli, A., Singla, L.D., Sharma, A., Bal, M.S., Filia, G. and Kaur, P. 2015. Molecular epidemiology, risk factors and hematochemical alterations induced by Theileria annulata in bovines of Punjab (India). Acta Parasitologica, 60(3): 378-390

Velusamy, R., Rani, N., Ponnudurai, G. and Anbarasi, P. 2014. Influence of season, age and breed on prevalence of haemoprotozoan diseases in cattle of Tamil Nadu, India. Vet. World, 7: 574-578.

Zaman, M.A., Mehreen, U., Qamar, W., Qamar, M.F., Kashif, M., Shahid, Z. and Abbas, R.Z. 2020. Brief account of bovine theileriosis prevalence in some South Asian countries. Agrobiol. Rec., 2: 38-48. 
